\title{
The relationship of the dilute whole blood lysis time to the fibrinolytic activity of blood: effect of change in plasma fibrinogen
}

\author{
J. A. HICKMAN', I. C. GORDON-SMITH, P. F. WHITFIELD, AND S. J. GODFREY
}

From the Department of Surgical Studies, the Middlesex Hospital, London

SYNOPSIS The rate of digestion of fibrin was measured in vitro by an isotopic technique in 140 blood samples of differing fibrinogen concentration; the assessment of fibrinolytic activity thus obtained was compared with a standard method of measurement, the dilute whole blood lysis time. The lysis time was related exponentially to the fibrinolytic activity as measured by the isotopic technique, and further was influenced markedly by alteration in the plasma fibrinogen concentration. The relevance of these observations to the use of lysis time methods for the measurement of fibrinolytic activity is discussed.

Two standard methods of measuring the fibrinolytic activity of blood involve setting up clotted samples of either diluted whole blood (MacFarlane, 1937; Fearnley, Balmforth, and Fearnley, 1957) or the diluted euglobulin fraction of plasma (MacFarlane and Pilling, 1946; Von Kaulla and Schultz, 1958)with subsequent incubation at $37^{\circ} \mathrm{C}$ and measurement of the time at which the clot disintegrates macroscopically. Difficulties inherent in both techniques include the lack of a precise endpoint and the presence of varying amounts of substrate, ie, fibrin, in the test system. Thus the interpretation of results when the fibrinogen concentration is abnormal or is changing from day to day is complicated by the difficulty of differentiating the effect of change in substrate concentration from change in actual fibrinolytic activity. The introduction of a simple isotopic method for measuring the rate of fibrin digestion in vitro (Hickman, 1971) has facilitated further scrutiny of the lysis time methods, particularly with respect to the influence of the plasma fibrinogen concentration and to the relationship of lysis time measurements to the fibrinolytic activity of the blood.

\section{Materials and Methods}

GENER AL

One hundred and forty blood samples were obtained

Address for correspondence: Dr J. A. Hickman, The London Hospital, Whitechapel, London, E1 1BB

Received for publication 10 January 1973. from patients over the age of 50 years in surgical wards: all these patients were receiving ${ }^{125}$ I-labelled fibrinogen for the detection of leg vein thrombosis. The fibrinogen preparation was processed at the Lister Institute from a pool of not more than five donors accredited by the Regional Transfusion Centres as free from the hepatitis carrier state. Iodination was carried out at the Radiochemical Centre, Amersham, Bucks, and the material was presented in freeze-dried form in ampoules containing $0.7 \mathrm{mg}$ fibrinogen and $100 \mu \mathrm{Ci}$ of ${ }^{125}$ Iodine. When this preparation was tested in vivo the amount of plasma radioactivity clottable by thrombin was usually between 80 and $93 \%$ of the total plasma radioactivity. In the unusual circumstance of a fibrinogen preparation having a 'clottability' in vivo of less than $80 \%$ it was discarded for use in the fibrinolytic assay since it was found that such preparations introduced inaccuracies into the isotopic measurements. Blood samples were taken with minimal haemostasis and glassware was washed both in acid and detergent.

PREPARATION OF BLOOD DILUENT MIXTURE Both the isotopic studies and the dilute whole blood lysis times (BLT) employed aliquots of the same mixture of blood and diluent. The mixture was prepared by adding, immediately after withdrawal, $10 \mathrm{ml}$ of whole blood to $85 \mathrm{ml}$ ice-cold acetate citrate diluent, $\mathrm{pH} 7 \cdot 4$, contained in a conical flask. The acetate citrate diluent was used, both because it increases the rate of fibrin digestion in vitro, the citrate ions inhibiting probably factor XIII, and the 
acetate ions inhibiting antiplasmin activity (Gallimore and Shaw, 1969), and because it has been claimed to allow the endpoint to be determined with greater accuracy (Gallimore, 1967). Aliquots of the blood diluent mixture were used for both the BLT and the isotopic measurements.

WHOLE BLOOD AND PLASMA FIBRINOGEN CONCENTRATION: DILUTE WHOLE BLOOD LYSIS TIME AND ISOTOPIC MEASUREMENTS OF FIBRINOLYTIC ACTIVITY

The techniques used were as described previously (Hickman, 1971). The principle of the isotopic method was to measure the rate of fibrin digestion in vitro. It was considered that this provided a more direct measurement of fibrinolytic activity than the lysis time methods, and that within normal ranges of activity it was largely independent of the fibrinogen concentration. This method has since been simplified (Hickman and Gordon-Smith, 1972).

FIBRINOGEN ENRICHMENT STUDIES

Studies involving the addition of fibrinogen in vitro were performed in order to determine whether the isotopic method of measuring fibrinolytic activity was truly independent of the fibrinogen concentration.

The fibrinogen solution was prepared by dissolving $1 \mathrm{~g}$ human lyophilized fibrinogen (Kabi Pharmaceuticals Ltd, London, W5) in $100 \mathrm{ml}$ sterile water. Aliquots of this solution were stored at $-20^{\circ} \mathrm{C}$ before use. Duplicate $15 \mathrm{ml}$ blood samples were taken into syringes containing either $2 \mathrm{ml}$ fibrinogen solution or $2 \mathrm{ml} 0.9 \%$ saline. The fibrinogen concentration, specific activity, and fibrinolytic activity for each sample were then measured using the techniques described above.

\section{Results}

Figure 1 shows fibrinolytic activity, as measured by the isotopic technique, plotted against the dilute whole blood lysis time. The results are shown in three groups according to the whole blood fibrinogen concentration. The low range corresponds to a whole blood fibrinogen concentration ranging between $0.81 \mathrm{mg}$ and $1.40 \mathrm{mg}$ per $0.5 \mathrm{ml}$ blood, corresponding to a plasma fibrinogen concentration of $290 \mathrm{mg} \%$ to $509 \mathrm{mg} \%$ (assuming a PCV of $45 \%$ ). The intermediate range corresponds to a whole blood fibrinogen concentration between $1.41 \mathrm{mg}$ and $2.00 \mathrm{mg}$ per $0.5 \mathrm{ml}$ blood (equivalent to a plasma fibrinogen concentration between $510 \mathrm{mg} \%$ and $727 \mathrm{mg} \%$ ) and the high range corresponds to ranges of $2.01 \mathrm{mg}$ to $2.60 \mathrm{mg}$ per $0.5 \mathrm{ml}$ blood (plasma fibrinogen $728 \mathrm{mg} \%$ to $924 \mathrm{mg} \%$ ). Such a range of plasma fibrinogen concentrations is by no means $\stackrel{\stackrel{0}{\vec{\sigma}}}{\underline{0}}$ unusual when studies include samples from subjects whose acute phase protein synthesis has been stimu- $\overrightarrow{\overrightarrow{0}}$ lated by factors such as surgical operation or infection. In postoperative subjects the whole blood, as against plasma, fibrinogen concentration is further increased by the tendency for the PCV to fall after operation. Thus the range of fibrinogen concentration will be greater when samples of whole blood are used as in the BLT than when samples of plasma are used as in the euglobulin lysis time.

The relationship between lysis time and fibrino- $\stackrel{\omega}{\circ}$ lytic activity is clearly not linear (fig 1). In fact $\overline{0}$ when attempts were made to obtain the highest correlation using different mathematical plots, the $\underset{\omega}{\sigma}$ logarithm of the lysis time plotted against the logarithm of fibrinolytic activity produced a higher $\infty$ coefficient of correlation $(r=0.7909)$ than either a 을 reciprocal plot $(\mathrm{r}=0.6586$ or a plot of the reciprocal $\rightarrow$ of the lysis time against the logarithm of fibrinolytic $z$ activity $(r=0.6834)$. Accordingly, regression lines obtained using the double logarithmic plot have $\stackrel{\Im}{工}$ been used to demonstrate the effect of fibrinogen $\overrightarrow{0}$ concentration upon the relationship of lysis time to $\omega$ fibrinolytic activity (fig 2). In fig 2 individual o regression lines obtained using a double logarithmic plot have been superimposed on the linear plot of the samples grouped according to their fibrinogen concentration as described previously. Each individual correlation coefficient shows a significant improvement (applying Fisher's ' $z$ ' transformation) on the overall correlation coefficient, and it will be seen that change in the fibrinogen concentration exerts a节 marked effect upon the relationship between slope and lysis time. The tendency of the regression lines 용 to merge at the higher range of activity suggests that $\overline{-}$ some degree of substrate enhancement occurs at this 3 . range of activity. The fact that, when plotted in this 8 way, the results are grouped according to fibrinogen concentration is suggestive that the isotopic method $\frac{\text { o }}{2}$ of measuring fibrinolytic activity, at least within the $>$ greater part of the physiological range of activity, is largely independent of the substrate concentration. $N$

Further evidence that the isotopic method is o independent of the fibrinogen concentration is $\tilde{O}$ obtained from the duplicate isotopic studies in which $N_{\omega}^{N}$ one series has been enriched by the addition of fibrinogen to the blood diluent mixture. In the 100 studies performed the lysis time was significantly $\underset{\mathbb{D}}{\overparen{D}}$ prolonged in each of the fibrinogen-enriched series $\stackrel{\circ}{+}$ but with only minor alteration in the slope (see table). $T$ An individual study is shown in figure 3 .

\section{Discussion}

Blix (1961) and Gallimore and Shaw (1969) both 

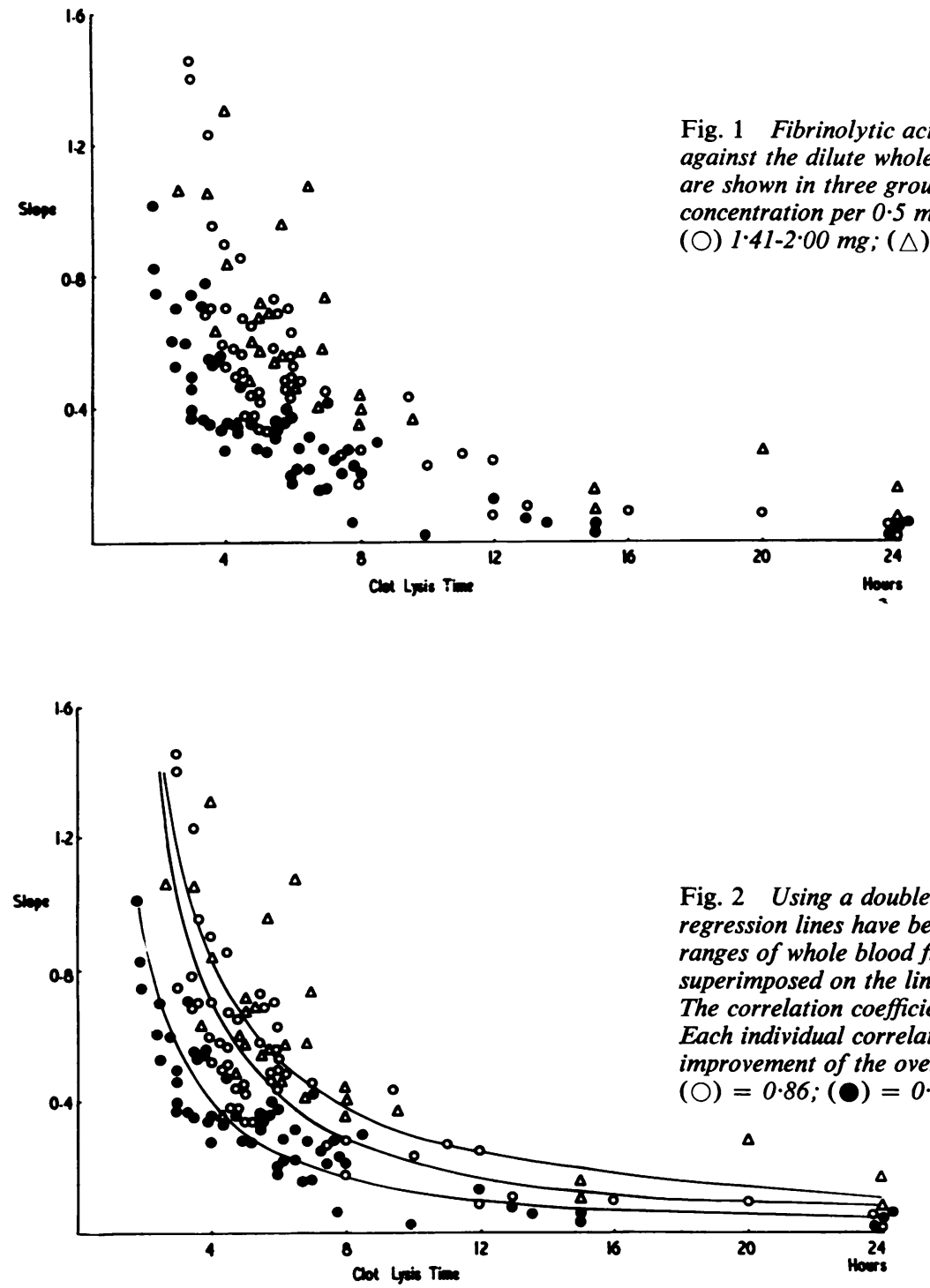

demonstrated that the addition of fibrinogen to blood samples prolonged the dilute whole blood lysis time. Blix further showed that the amount of fibrinogen in the eugloblin precipitate of plasma was determined by the plasma fibrinogen concentration, indicating that the euglobulin lysis time would be affected similarly by change in plasma fibrinogen. It was not possible, however, to quantitate this effect using their in vitro methods, and scepticism has been expressed on the validity of the findings based as they were on manipulation in vitro of the fibrinogen concentration. The present study in fact confirms their finding and provides some guidance on the magnitude of the effect exerted by change in plasma fibrinogen. It becomes evident from a study of fig 2 that in situations where the fibrinogen concentration has altered significantly an assessment of fibrinolytic activity by lysis time methods will be difficult to interpret. For example, one can question to what extent the so-called fibrinolytic 'shutdown' occurring after injury (Innes and Sevitt, 1964; Chakrabarti, Hocking, and Fearnley, 1970) is a reflection of the increased fibrinogen concentration rather than an actual reduction of net enzyme 


\begin{tabular}{|c|c|c|c|c|c|c|}
\hline \multirow[t]{2}{*}{ Study } & \multicolumn{2}{|c|}{$\begin{array}{l}\text { Fibrinogen Concentration } \\
(\mathrm{mg} / 100 \mathrm{ml} \text { plasma })\end{array}$} & \multicolumn{2}{|l|}{ Slope } & \multicolumn{2}{|c|}{$\begin{array}{l}\text { Whole Blood Lysis Time } \\
(\mathrm{hr})\end{array}$} \\
\hline & Control & Enriched & Control & Enriched & Control & Enriched \\
\hline 1 & 204 & 493 & 0.78 & 0.76 & 2 & $3 \cdot 5$ \\
\hline 2 & 234 & 465 & 0.22 & 0.28 & 4 & 6 \\
\hline 3 & 239 & 442 & 0.49 & 0.44 & 3 & 4 \\
\hline 4 & 498 & 748 & 0.07 & $0 \cdot 18$ & $>24$ & 24 \\
\hline 5 & 475 & 734 & 0.75 & 0.81 & $3 \cdot 5$ & $4 \cdot 5$ \\
\hline 6 & 494 & 689 & 0.94 & 0.94 & 3 & $4 \cdot 5$ \\
\hline 7 & 200 & 489 & 0.82 & 0.73 & $2 \cdot 5$ & 3 \\
\hline 8 & 368 & 548 & 0.51 & 0.52 & $3 \cdot 5$ & $4 \cdot 5$ \\
\hline 9 & 553 & 778 & 1.64 & $1 \cdot 34$ & $1 \cdot 5$ & 2 \\
\hline 10 & 670 & 754 & 0.72 & 0.55 & 3.5 & 6 \\
\hline
\end{tabular}

Table The results in 10 studies of the effect of the addition of fibrinogen in vitro to one of a pair of duplicate samples

Using Student's t test there is no significant difference between the slopes (P $0 \cdot 3)$ but there is a significant difference between the whole blood lysis time groups (P 0.001).

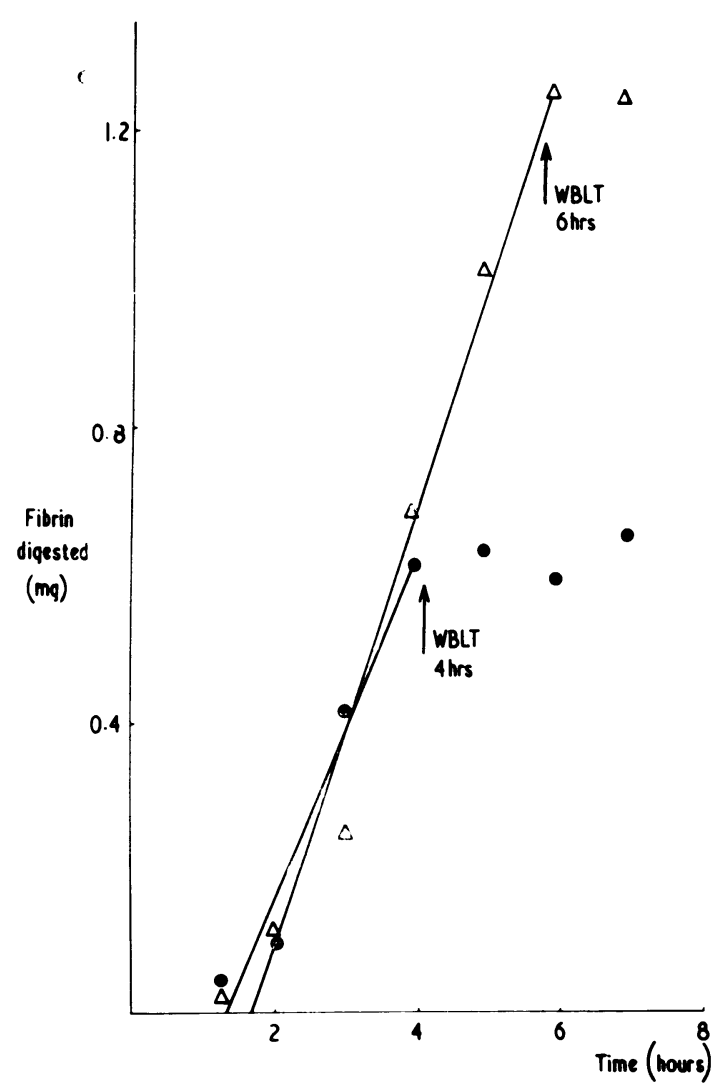

Fig. 3 Fibrinogen enrichment study no. 2 is illustrated. The fibrinogen concentration has been increased from 234 $\mathrm{mg} \%$ in the first sample (O) to $465 \% \mathrm{mg}$ in the second sample $(\triangle)$. This has prolonged the whole blood lysis time from four to six hours with only minor alterations in the rate of the reaction. activity. Certainly the studies of this phenomenon have relied heavily on lysis time methods and it is noteworthy that the 'shutdown' occurs during a period when not only is the plasma fibrinogen concentration raised, but the presence of fibrin degradation products in the serum suggests that the proteolysis of fibrin is actually increased.

However, quite apart from the technical difficulties described above, there are more basic problems involved in assessing the significance of measurements of the fibrinolytic activity of circulating blood. For example, individual measurements of activity obtained by any method can be of only limited significance in view of the wide fluctuation of activity that is present in most individuals. Furthermore, activity in a sample of peripheral venous blood may bear little relationship to activity in other blood vessels or to activity at the vessel wall, and in isolation gives little information on the balance between fibrinolytic enzymes and their inhibitors. Again, that fibrin degradation products appear in the serum at a time when the fibrinolytic activity of blood cannot be shown to be increased and may actually appear reduced is a further interesting anomaly casting real doubt on the validity of this approach to the measurement of fibrinolysis.

It is a pleasure to thank Professor L. P. Le Quesne and $\mathrm{Mr} \mathrm{M}$. Hobsley for their encouragement and constructive criticism, $\mathrm{Mr}$ B. Newman for his advice, and Mrs Mary Groves for her secretarial assistance.

\section{References}

Blix, S. (1961). The fibrinolysis of plasma clots under various conditions. Acta med. scand., 169, 495-502.

Chakrabarti, R., Hocking, E. D., and Fearnley, G. R. (1969). Reaction pattern to three stresses-electroplexy, surgery, and myocardial 
infarction - of fibrinolysis and plasma fibrinogen. J. clin. Path., 22, 659-662.

Fearnley, G. R., Balmforth, G., and Fearnley, E. (1957). Evidence of a diurnal rhythm; with a simple method of measuring natural fibrinolysis. Clin. Sci., 16, 645-650.

Gallimore, M. J. (1967). Effect of diluents on blood clot lysis. J. clin. Path., 20, 234-238.

Gallimore, M. J., and Shaw, J. T. (1969). The influence of various plasma components on the lysis of dilute human blood clots. Thrombos. Diathes haemorrh. (Stuttg.), 22, 223-233.

Hickman, J. A. (1971). A new technique for the quantitative estimation of fibrinolysis using in vivo [125I] fibrinogen. Brit. J. Haemat., 20, 611-621.
Hickman, J. A., and Gordon-Smith, I. C. (1972). Timed fibrin digestion: simplified technique for the measurement of the fibrinolytic activity of the blood. J. clin. Path., 25, 191-193.

Innes, D., and Sevitt, S. (1964). Coagulation and fibrinolysis in injured patients. J. clin. Path., 17, 1-13.

MacFarlane, R. G. (1937). Fibrinolysis following operation. Lancet, $1,10-12$.

MacFarlane, R. G., and Pilling, J. (1946). Observations on fibrinolysis: plasminogen, plasmin, and antiplasmin content of human blood. Lancet, 2, 562-565.

Von Kaulla, K. N., and Schultz, R. L. (1958). Methods for the evaluation of human fibrinolysis: studies with two combined technics. Amer. J. clin. Path., 29, 104-112.

\section{The February 1973 Issue}

\section{THE FEBRUARY 1973 ISSUE CONTAINS THE FOLLOWING PAPERS}

Azotaemic renal osteodystrophy: a quantitative study on iliac bone H. A. ELLIS AND KATHLEEN M. PEART

Identification of intrarenal fibrin deposition A. M. DAVISON, D. THOMSON, MARY K. MACDONALD, J. K. RAE, W. S. UTTLEY, AND A. R. CLARKSON

Electron microscope study of a case of Australia antigen-positive chronic hepatitis JUNE D. ALMEIDA, P. GIOANNINI, G. SCALISE, AND C. V. HARRISON

Intravascular coagulation and $E$. coli septicaemia F. E. PReston, R. G. MALIA, M. J. SWORN, AND E. K. BLACKBURN

Variable sex chromatin pattern in an early carcinoma of the bladder N. B. ATKIN AND I. PETKOVIĆ

The effect of pancreatectomy and other agents on iron absorption and storage in the rat R. SINNIAH, T. K. BELL, AND D. W. NEILL
Neonatal meningitis caused by Citrobacter koseri R. J. GROSS, B. ROWE, AND J. A. EASTON

Controlling infection in a district general hospital PAUL NOONE AND M. S. SHAFI

Bacteriological hazards of disposable bedpan systems G. L. GIBSON

Gentamicin as a selective agent for the isolation of beta haemolytic streptococci WILLIAM A. BLACK AND FRANCES VAN BUSKIRK

\section{Technical methods}

A replica technique for paraffin sections for transmission electron microscopy LILIAN LIM

Simplified procedure for the detection of antigens by crossed immunoelectrophoresis J. W. KEYSER AND K. LEWIS

Letters to the Editor

Book review

Copies are still available and may be obtained from the PUBLISHING MANAGER, BRITISH MEDICAL ASSOCIATION, TAVISTOCK SQUARE, WC1H 9JR, price $£ 1.05$ 